TÍTULO ORIGINAL, "Dentro del corredor de la muerte" (Documental), AÑO: 2009, DURACIÓN: 47 minutos,

PAÍS: Estados Unidos,

PRODUCTORA: Mannucci, Inc en asociación con National Geographic Television para National

Geographic Channel,

GENERO: Documental.

\title{
Dentro del corredor de la muerte
}

En este documental se expone la pena capital en Texas (Estados Unidos), a través de la historia de tres hombres condenados a pena de muerte, en el penal de máxima seguridad Polunsky de la cuidad de Huntsville, en dicha instalación se encuentra el llamado "Corredor de la muerte de Texas".

Los condenados a muerte son trasladados desde la prisión hacia el lugar donde se llevará a cabo su ejecución en un transporte que modifica su ruta en cada uno de los traslados que realiza; el prisionero está informado de la hora y el lugar en que será ejecutado por medio de inyección letal.

Las ejecuciones realizadas son muy frecuentes, por lo que los habitantes de la ciudad lo ven como algo habitual. En el estado de Texas, desde 1924 hasta la fecha en la que se realizó el documental, se habían ejecutado a más de 1,000 prisioneros.

Son presentados los casos de Willie Earl Pondexter Jr., Johnny Ray Johnson y David Martínez todos condenados a muerte por asesinato, en cada uno de los casos se describen las circunstancias y motivos que los llevaron a cometer dichos delitos. Además se expone la situación actual de encierro, cómo les afecta el poco contacto entre presos y cómo cada uno de ellos se enfrenta a la idea de que pronto se realizará su ejecución. Las opiniones de los familiares tanto de los presos como los de las víctimas y las personas que conocen o apoyan en sus últimos momentos; se van sucediendo en medio de la lucha porque se suspenda legalmente la ejecución o lograr aplazamientos de la misma; aunque escaseen los casos en los que se ha conseguido.

Se presentan los procedimientos en cada una de las ejecuciones, el trato en general que reciben los condenados, las experiencias que ha tenido el personal que participa en ellas, las posturas de las personas que están a favor o en contra de la pena de muerte. A través de todos estos elementos se puede tener una visión más amplia sobre tan sensible tema.

Sinopsis a cargo de Carlos Roberto Escobar Beltrán Unidad de Acceso a la Información Pública UAIP.ANSP 